\title{
STUDY OF ACTIVATION OF COAL CHAR
}

ANNUAL TECHNICAL PROGRESS REPORT

JULY, 2000 - JUNE, 2001

E. M. SUUBERG (PRINCIPAL INVESTIGATOR)

I. KÜLAOTS (STAFF)

I. AARNA, M. CALLEJO (STUDENTS)

Date of Original Preparation : November, 2001

Date of Revised Format: July, 2003

DOE Grant Number DE-FG26-99FT40582

Submitted by:

DIVISION OF ENGINEERING

BROWN UNIVERSITY

PROVIDENCE, RI 02912

TEL. (401) 863-1420

"US/DOE Patent Clearance is not required prior to the publication of this document" 


\section{United States Government Disclaimer}

This report was prepared as an account of work sponsored by an agency of the United States Government. Neither the United States Government nor any agency thereof, nor any of their employees, makes any warranty, express or implied, or assumes any legal responsibility for the accuracy, completeness, or usefulness of any information, apparatus, product, or process disclosed or represents that its use would not infringe privately owned rights. Reference herein to any specific commercial product, process, or service by trade name, trademark, manufacturer, or otherwise does not necessarily constitute or imply its endorsement, recommendation, or favoring by the United States Government or any agency thereof. The views and opinions of the authors expressed herein do not necessarily state or reflect those of the United States Government or any agency thereof. 


\begin{abstract}
This is the second report on a project whose aim is to explore in a fundamental manner the factors that influence the development of porosity in coal chars during the process of activation. It is known that choices of starting coal, activating agent and conditions can strongly influence the nature of an activated carbon produced from a coal.

This work has again confirmed that there is a fundamental difference in char structure that is reflective of the source of the chars. What is new in the present results is a strong indication that this difference is seen, irrespective of the conditions of char preparation. Results were compared for utility combustion chars, all of which were prepared under the very high intense heating conditions of utility boilers, and the laboratory-prepared chars prepared at orders of magnitude lower heating rates. The chars were of very similar nature regardless of the heating conditions that led to their preparation (and despite major differences in level of burnoff).

On the other hand, the results from the examination of the laboratory char results do again suggest that the activation conditions play some role in determining porosity, though their effect is decidedly less important than the role of the parent material. This is true despite an enormous range of reactivity exhibited by the activating agents.
\end{abstract}


Table of Contents

$\begin{array}{lc}\text { INTRODUCTION } & 5 \\ \text { EXECUTIVE SUMMARY } & 7 \\ \text { EXPERIMENTAL } & 8 \\ \text { RESULTS AND DISCUSSION } & 9 \\ \text { CONCLUSIONS } & 15 \\ \text { REFERENCES } & 16\end{array}$




\section{INTRODUCTION}

Coal is an important feedstock for the preparation of certain kinds of activated carbon products, and there continues to be significant interest in developing other high value added products from coals. One of the main difficulties associated with the development of products is the highly empirical nature of the process. Attempts to introduce a new feedstock or new activation condition require a great deal of experimental investigation, since no reliable predictive models of the porosity development process are available. This is attributable to the complexity of the processes that are involved. There are many factors that determine the characteristics of activated carbons obtained from any starting material. One of the factors is the chemical nature of the starting material. Another is the pyrolysis conditions. Also important are the nature of the activation process as well as whether the material contains any catalytic agents. Finally, some of the results that have been previously presented in the literature might have been influenced by some misunderstanding of how the gas adsorption techniques used for characterization actually influence the conclusions.

The present program initially involves a heavily experimental component, and we will use these results to guide modeling efforts. The main characterization methods include gas adsorption techniques, and the activation is being conducted in a wide range of gaseous environments.

Char porosity and surface area are important in the combustion and gasification processes of coals. There is evidence that there is a transition to a partially pore-transport controlled regime, even in pulverized combustion in which external transport control dominates early on. Intrinsic reaction rate shows itself as a factor in determining final char burnout kinetics [1]. Though still debated, the majority opinion remains that the correct way to express char reactivities is on a surface area basis [2]. There is also importance in understanding the "activation" of coal chars, since this process is essential to producing activated carbons from coals. Several models have been advanced which describe the development of surface area with burn-off [3-9]. The models have been developed to varying levels of complexity. These models are all presently independent of the nature of the reactive gas, but it has been observed that very different patterns of porosity development are 
possible, even when attempts are made to match the rates of reaction of a particular char in different reactant gases [10].

This report presents the results of an experimental study on some aspects of the development of porosity in oxidizing gases, and tracks development to quite high levels of burnoff. It begins to examine the question of how sensitive to the nature of the oxidizing gas the porosity development actually is. Is it mainly the carbon material itself, or is it the activation conditions, that determine the nature of the porosity that is developed? 


\section{EXECUTIVE SUMMARY}

During the present period of the project, several important issues have been examined. The same experimental techniques that were reported previously have again been utilized in this part of the study. Coals have been initially pyrolyzed to create carbonaceous chars. As before, some the the chars were produced in a laboratory furnace. These samples were heated in inert gas at tens of degrees per minute to temperatures in the vicinity of $1000^{\circ} \mathrm{C}$. Other very different kinds of samples have been collected from utilities that burn coal as a fuel. These chars were produced at heating rates of tens of thousands of degrees per second to temperatures that might typically reach $1700^{\circ} \mathrm{C}$. Moreover, these chars were produced under strongly oxidizing conditions, such that well over $99 \%$ of the carbonaceous char was consumed. These vastly different pyrolysis regimens gave very surprisingly similar chars.

It has been concluded that over an enormous range of pyrolysis conditions, ranging from slow heating in laboratory furnaces to the rapid heating characteristic of utility boilers, coal chars are remarkably similar. It is the choice of starting coal that mainly determines the nature of the char that is formed. The thermosetting low rank coals always give "better" activated carbon precursors (when the present physical activation methods are employed). Their structures have an enormous amount of free volume "built in" during pyrolysis, be it fast or slow. On the other hand the thermoplastic higher ranks coals (the bituminous coals) lose virtually all of their free volume during the softened stage, and can never fully recover it. This free volume is the origin of the micropores and surface area duing activation.

There has also been some considerable debate in the literature concerning the "best" adsorptive for characterizing chars. There is in certain quarters a strong belief that carbon dioxide offers a better picture of porosity than nitrogen, because the former is better able to penetrate diffusionally "tight" pores of a char. The present results show that this is probably a poor criterion for the choice of carbon dioxide over nitrogen for two reasons. The first is, that upon even a small extent of activation, the char becomes equally accessible to both adsorptives. The second reason is that the carbon dioxide, because of its inability to fill larger micropores, will not see all of the existing porosity in the way that nitrogen can. What this means is that during the course of activation, carbon dioxide might well provide a false impression of when micropore volume has reached a maximum; the maximum in carbon dioxide's ability to fill pores does not coincide with the actual maximum in IUPAC microporosity. Also, the carbon dioxide is of little value in characterizing anything but the smaller micropores, as it cannot fill any mesopores. 


\section{Experimental}

Controlled experiments have been performed on chars derived from coal samples (particle size $<150 \mu \mathrm{m})$ obtained from the Argonne Premium Coal Sample Bank [11]. Samples were pyrolyzed in a tube furnace at $1273 \mathrm{~K}$ for two hours, in flowing helium. The resulting chars were gasified in an Online Instruments TG-plus TGA system. Gasification was performed in flowing mixtures of helium and reactant gas $\left(\mathrm{O}_{2}\right.$, NO or $\left.\mathrm{CO}_{2}\right)$. Samples of 30-50 $\mathrm{mg}$ were dispersed on circular platinum pans with a large flat surface, resulting in a particle beds of about $1 \mathrm{~mm}$ thickness. Temperatures were selected to assure that gasification took place under reaction rate controlled (socalled "Zone I") conditions. Adsorption isotherms were determined for product chars using an automated volumetric gas adsorption apparatus (Autosorb 1, Quantachrome Co.). Adsorption of N2 and $\mathrm{CO} 2$ were performed at $77 \mathrm{~K}$ and $195 \mathrm{~K}$, respectively. We feel that nitrogen offers the more complete and accurate picture of porosity, despite the well-known problem of activated diffusional limitations at near-zero burn-off [10, see below]. Before measurements, samples were outgassed for several hours in vacuum at temperatures in the range $573-673 \mathrm{~K}$.

Comparison has been made between the laboratory chars and chars that have been received from commercial utilities. In this latter case, the chars are actually the unburned carbon fractions of the coal fuel burned under pulverized firing conditions. There is always some residual unburned carbon present in utility fly ashes. These materials have been the subject of another study in this laboratory [e.g.,12], but here the focus is on the porous nature of these end-stage burnout chars.

\section{Results and Discussion}

It was shown previously [10] that many conclusions regarding the development of porosity in coal chars could be strongly influenced by the choice of adsorptive; following the line of investigation suggested in [13], it was demonstrated that nitrogen was a better general adsorptive probe than carbon dioxide. It is still the case that $\mathrm{CO}_{2}$ gives higher apparent surface areas 
(micropore volumes) than does $\mathrm{N}_{2}$ at low burnoffs. Figure 1 shows the comparison of the results obtained using these two adsorptives on chars that had been gasified in three different gaseous environments. The plot emphasizes the low burnoff regime.

The zero burnoff value for the $\mathrm{CO}_{2}$ adsorptive is significantly higher than that for the $\mathrm{N}_{2}$ adsorptive, but the former value is quite near that which the $\mathrm{N}_{2}$ values quickly assume. It is unreasonable to believe that there takes place some special process by which pores that can be examined by nitrogen, but not carbon dioxide, are created only at very low values of burnoff. Since diffusional limitations have already been concluded to exist at nitrogen adsorption conditions, it is more likely that what is responsible for the convergence of the nitrogen and carbon dioxide results is the loss of the diffusional limitations with limited amounts of carbon removal.

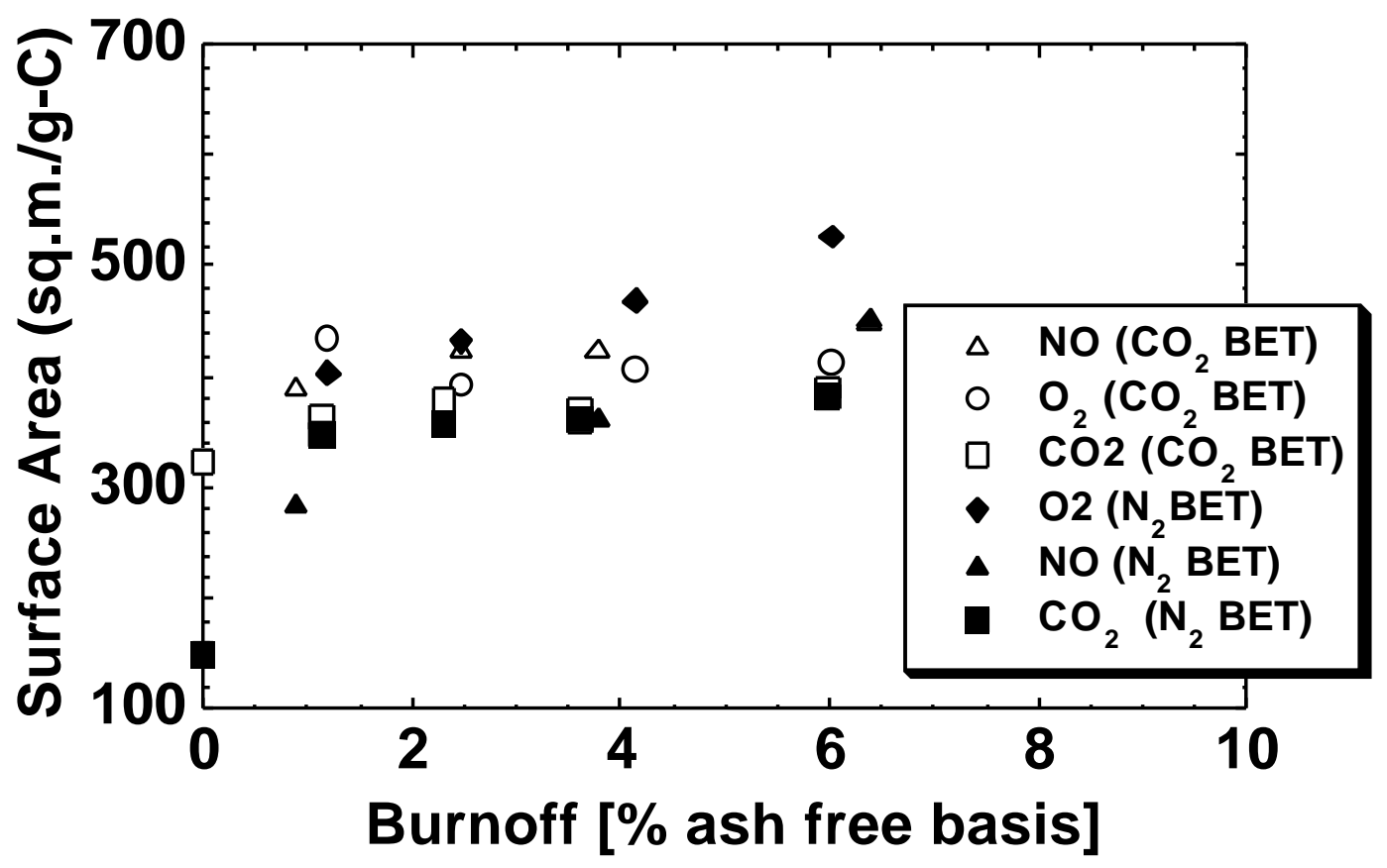

Figure 1. The BET surface areas of Wyodak subbituminous coal chars gasified in $\mathrm{O}_{2}(717$ $\mathrm{K}, 2.02 \mathrm{kPa})$, NO ( $911 \mathrm{~K}, 0.82 \mathrm{kPa})$, and $\mathrm{CO}_{2}(1007 \mathrm{~K}, 4.80 \mathrm{kPa})$, measured using $\mathrm{CO}_{2}$ adsorption (open points) and $\mathrm{N}_{2}$ adsorption (closed points). 
Thus it seems that the microporosity that is apparently "created" mostly already exists and that it is indeed hindered diffusion of $\mathrm{N}_{2}$ into small pore openings that is the source of an artifact at $0 \%$ burnoff. Microporosity is equally well characterized by both adsorptives at just above $0 \%$ burnoff. At this stage, there is no difference in porosity development in different reactants. Thus it appears that roughly $400 \mathrm{~m}^{2} / \mathrm{g}$ is an intrinsic initial value for this char, accepting as usual the fact that the BET model is only a crude indicator of microporosity. These data also support the view that all of this porosity is already present at the end of pyrolysis and it is unnecessary to base a model of the porosity development due to carbon removal processes on these low burnoff results. Instead, these processes probably involve very subtle relaxation of the structure to some very limited degree, allowing the easier penetration of nitrogen. It would not be particularly surprising if protruding carbon atoms at pore mouths were the locus of initial chemical attack relatively independently of nature of reactant. It is, however, clear that when the same samples are tracked to higher burnoffs, the effects of reactant gas begin to show themselves (see Figure 2). The question is what determines the very different patterns in the different gases at higher burnoffs. 


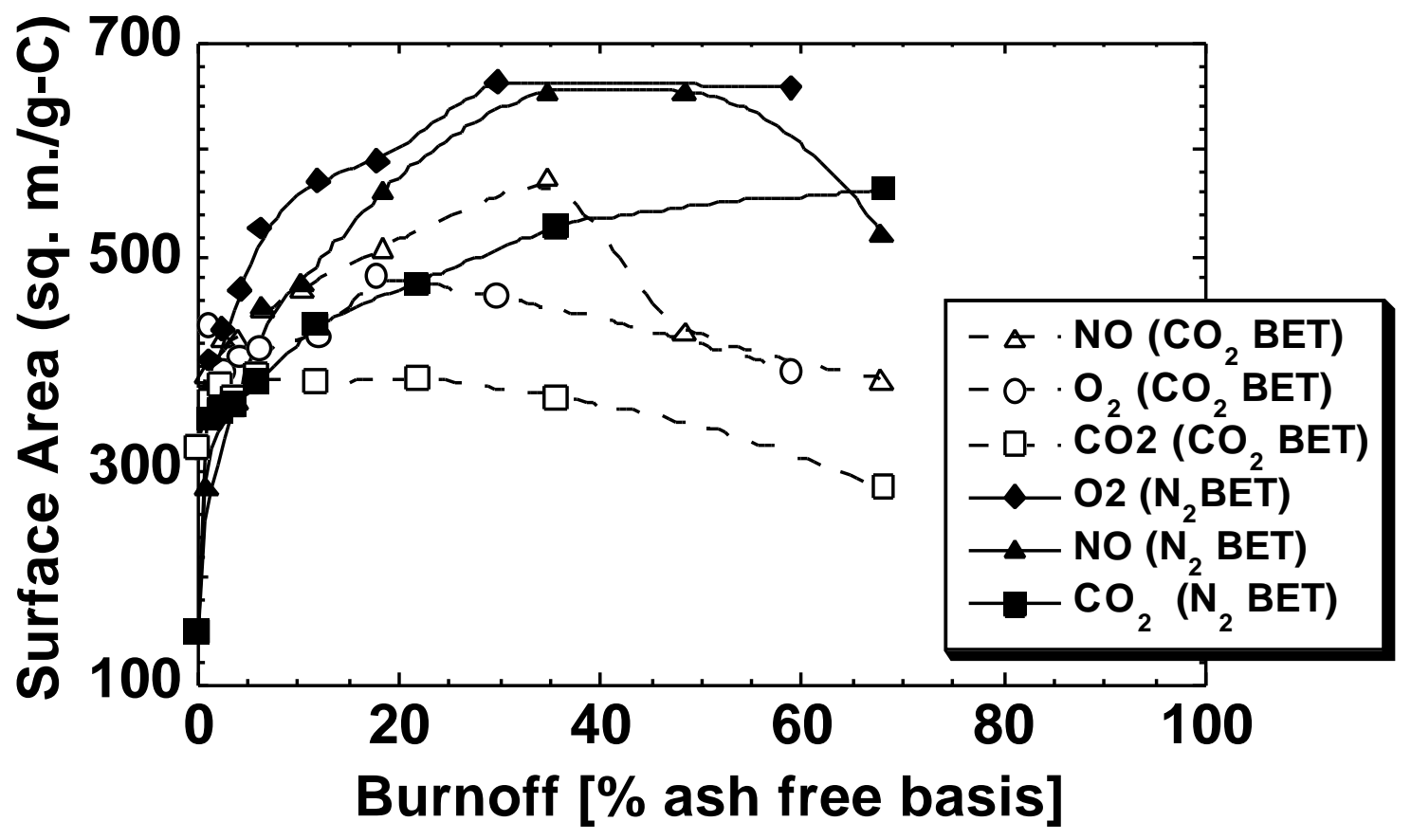

Figure 2. The data of Figure 1, extended to higher burnoffs.

In Figure 2, the already documented inadequacy of $\mathrm{CO}_{2}$ as an adsorptive probe shows itself clearly [10]. The nitrogen BET results show a rise to some limiting values of surface area, and only at very high burnoffs in one case is a decline seen. It should be noted that these are results calculated to a gram of carbon basis, exclusive of the ash content. Since the ash content of the char is essentially non-porous, to not recalculate to a carbon basis provides a misleading picture of how the porosity in the carbon portion is behaving; this latter point has been overlooked in some of the published literature on this topic.

Figure 2 shows that there is an apparent loss of porosity at low burnoffs when the chars are examined using carbon dioxide as the adsorptive. Again, this phenomenon is well-known [10] and attributed to the inability of the carbon dioxide to fill the larger micropores, for reasons of 
thermodynamic instability of the condensed phase. On this basis, the decision has been made in this project to use nitrogen as the primary adsorptive for characterizing the chars.

The small differences in porosity development attributable to reactant gas, seen with the Wyodak low rank coal, are mirrored in results from higher rank coals, as seen in Figure 3. Again, the reaction conditions of temperature and partial pressure for each gas were selected to give as close a match as possible between the rates in those gases.

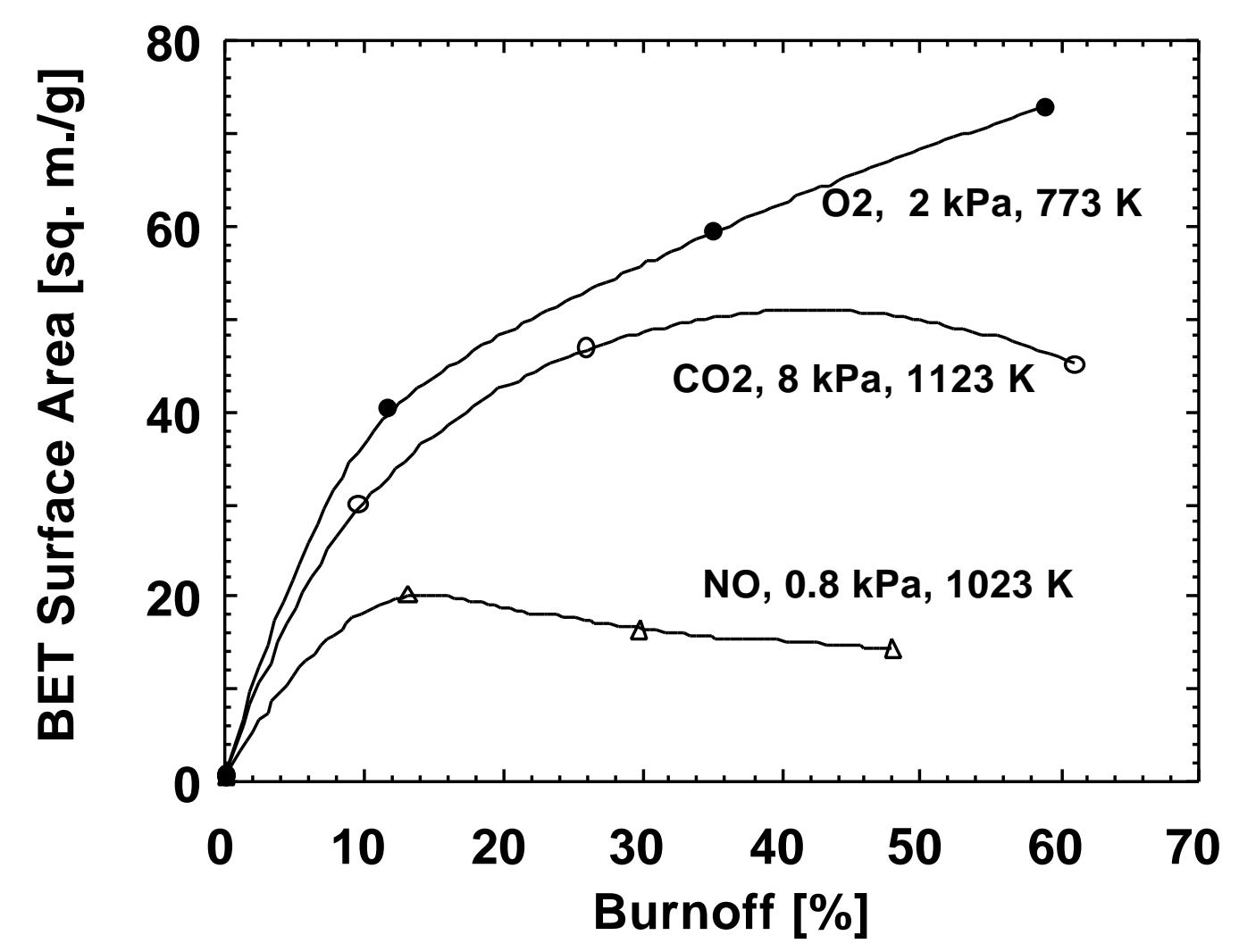

Figure 3. Development of porosity in Pittsburgh No. 8 bituminous coal.

The bituminous coal shows much lower surface area than did the subbituminous, as is generally the case. The ordering of porosity development in the various gases is also different from that observed in the Wyodak coal. The differences in initial char morphology can be understood in terms of differences arising from pyrolysis- the bituminous coal softens and loses fine porosity, whereas the subbituminous coal is thermosetting and retains fine porosity during pyrolysis. What 
is as yet unexplained is the differences in patterns of pore development in the different gases.

The question of whether the differences in char morphology are influenced by pyrolysis conditions was addressed by examining the chars produced under very different kinds of conditions. Results for chars produced under extremely high heating rates are seen in Figure 4.

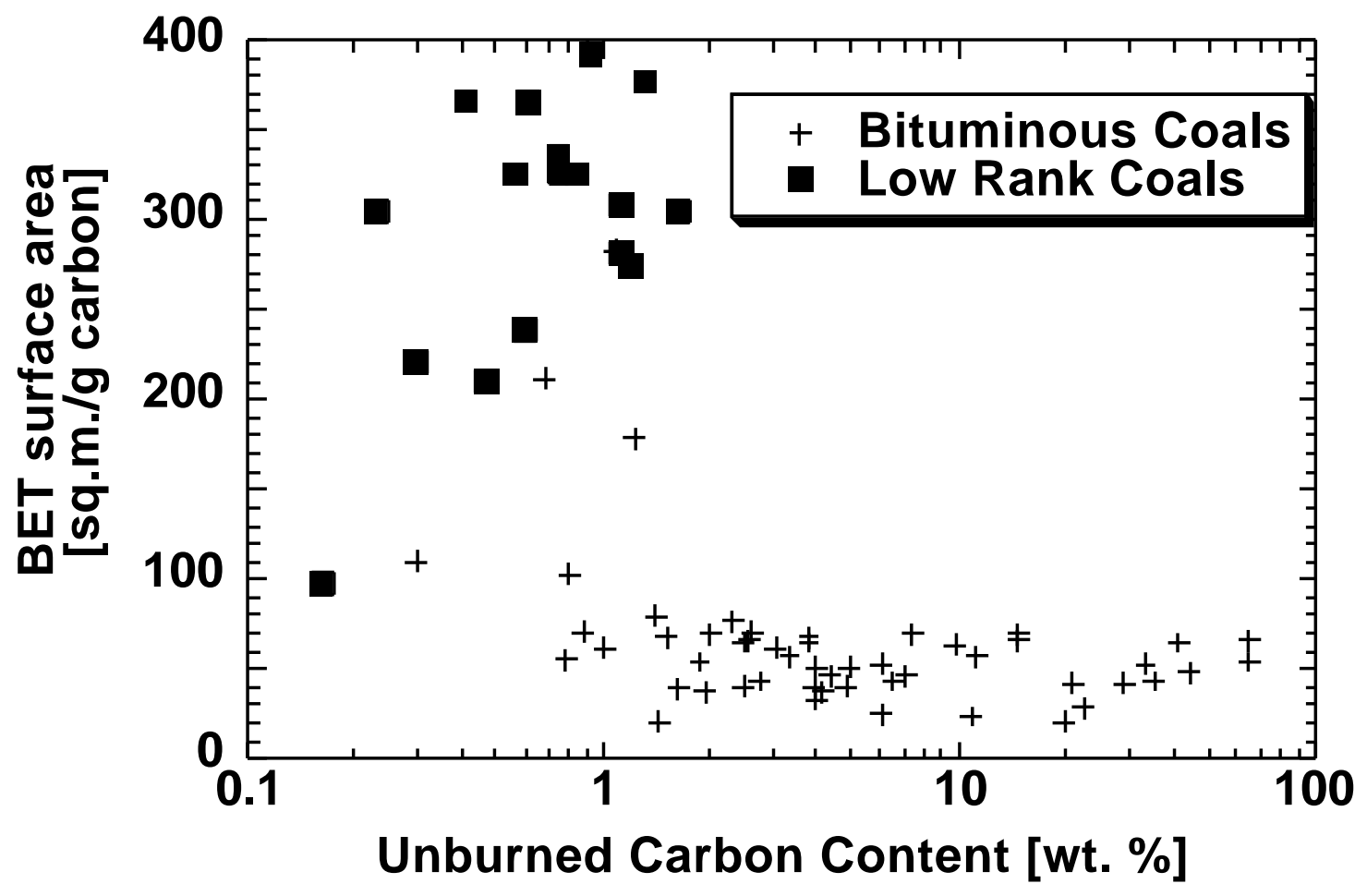

Figure 4. The surface areas of pulverized firing coal chars, shown as a function of unburned carbon content in fly ash.

We had already reported that the differences in char morphology could be observed under laboratory burner conditions [14], but how important this factor was as an actual design parameter for production of activated carbons remained unclear. It may, however, quickly be seen from Figure 4 that the earlier noted differences in char morphology imprinted during pyrolysis can persist until the very final stages of burnout of the chars (all of the samples in Figure 4 have an equivalent char 
conversion of well over $99 \%$ ).

The initial values of surface area were of course not available for these commercial samples, so in the few cases that involve unusually high or low surface areas for the particular rank of coal, it is unclear whether this was present already during pyrolysis or not.

It was suspected that the commercial samples were produced under pulverized firing conditions that were at least partially external transport limited. Because of this, it was reasoned that the final porosity of these samples might be more representative of initial porosity than that which would develop under Zone I conditions. This hypothesis was tested by subjecting two different samples of unburned fly ash char, from bituminous coals, to Zone I reaction conditions in air at 770 K. The initial surface area of both chars was typical of the great majority of samples derived from this rank (about 40-60 $\mathrm{m} 2 / \mathrm{g}$, which is also comparable to the low burn-off values for the laboratory char (see Figure 3).

The results in Figure 5 make a strong case that the samples had not seen pure Zone I conditions in the boiler and thus could not fully develop their porosity. They are more typical of the very low burn-off bituminous chars of Figure 3, but can be induced to follow a very similar pattern of porosity evolution under Zone I conditions in oxygen. Thus it appears as though the samples in Figure 4 show a porous character that is basically set during pyrolysis, and is not very much altered thereafter, except for elimination of the nitrogen diffusional barriers.

The major differences between softening high rank coals and non-softening low rank coals persist over the entire course of burn-out, as the results of Figure 4 would indicate. There is, moreover, a remarkable degree of similarity in samples from a wide range of sources, though admittedly with a few exceptions in both bituminous and low rank categories. 


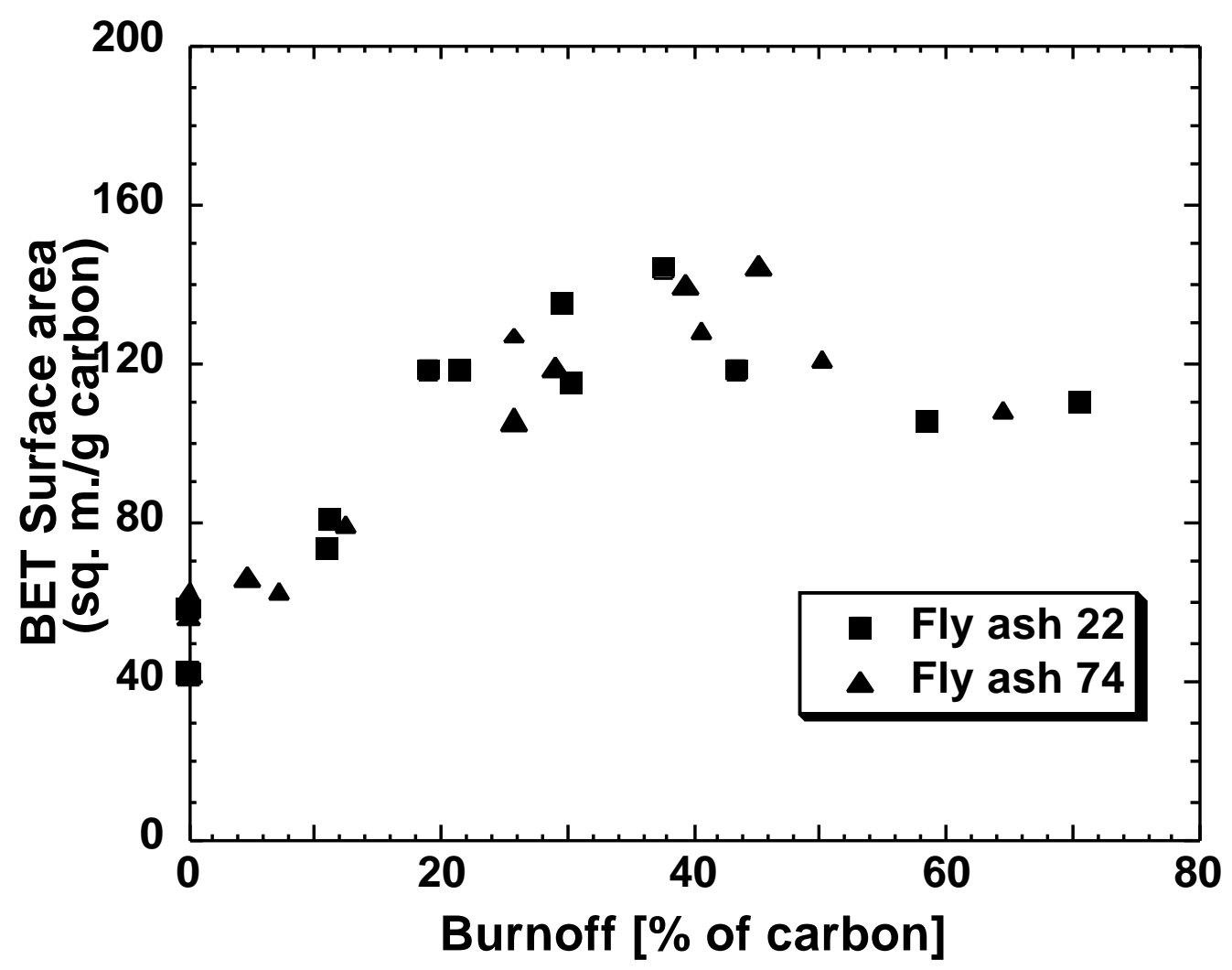

Figure 5. Development of surface area in coal chars from pulverized firing. Burn-off refers to an initial state as it exists in fly ash, i.e., after $>99 \%$ burn-off of the original coal. Chars were burned off in air at $770 \mathrm{~K}$.

\section{Conclusions}

This work has clearly established that there is a fundamental difference in char structure that is reflective of the source of the chars. This may be seen from both the results for the utility combustion chars, all of which would have been formed and burned out under very similar conditions, as well as from a comparison of the laboratory-prepared chars. On the other hand, the results from the examination of the laboratory char results do suggest that the activation conditions play some role in determining porosity, though their effect is decidedly less important than the role 
of the parent material. This is true despite an enormous range of reactivity exhibited by the activating agents.

\section{References}

1. Beeley, T., Crelling, J., Gibbins, J., Hurt, R., Lunden, M., Man, C., Williamson, J., Yang, N. Proc. Int. Symp. on Combustion, 1996, 26, 3103.

2. Smith, I.W., Proc. Int. Symp. on Combustion,1982, 19,1045.

3. Ballal, G.; Zygourakis, K. I\&EC Res. 1987, 26, 911.

4. Bhatia, S.K.; Perlmutter, D.D. AIChEJ, 1980, 26, 379.

5. Gavalas, G. R. Comb. Sci. Tech., 1981, 24, 197.

6. Kantorovich, I.I.; Bar-Ziv, E. Comb. Flame, 1994, 97, 61.

7. Simons, G.A. Prog. Energy Comb. Sci., 1983, 9, 269.

8. Bhatia, S.K.; Vartak, B.J. Carbon, 1996,34, 1383.

9. Sahimi, M.; Gavalas, G.R.; Tsotsis, T.T. Chem. Eng. Sci., 1990, 45, 1443.

10. Aarna, I.; Suuberg, E.M. Proc. Int. Symposium on Comb.,27, 1998, 2933.

11.Vorres, K.S., Energy Fuels, 1990, 4,420.

12. Freeman, E.; Gao, Y.M.; Hurt, R.H.; Suuberg, E.M., Fuel,1997, 76, 761.

13.Rodríguez-Reinoso, F., Linares-Solano, A., in Chemistry and Physics of Carbon, Vol. 21, P. A. Thrower, Ed., Dekker, New York, 1989, p 1.

14. Hachmann, L.; Burnett, A.; Gao, Y.M.; Hurt; R.H.; Suuberg, E.M. Proc. Int. Symposium on Comb.,27, 1998, .2965. 